\title{
Cerrahi Müdahale Gerektiren Olanzapin İlişsili Paralitik İleus Olgusu
}

\section{A Case of Olanzapine-related Paralytic Ileus Necessitating Surgical Intervention}

\section{Halil İbrahim Taşcı}

TC Sağlık Bakanlı̆̆ı, Dr.Ersin Arslan Eğitim ve Araștırma Hastanesi, Genel Cerrahi Kliniğgi, GAZİANTEP

Yazı̧ıma Adresi / Correspondence:

Halil İbrahim Taşcı

TC Sağlık Bakanlığı, Dr.Ersin Arslan Eğitim ve Araştırma Hastanesi, Genel Cerrahi Kliniği, GAZİANTEP

T: +905054810445 E-mail: okcu6528@gmail.com

Geliş Tarihi / Received : 12.02.2019 Kabul Tarihi / Accepted : 27.02.2019

Öz

Opioid analjezikler, trisiklik antidepresanlar, antihistaminikler ve antipsikotik ilaçlara bağlı ileus gelișebilmektedir. Bipolar bozukluk tanısı ile yaklașık otuz yıldır takipli olan 54 yaşında erkek hasta 5 gündür olan karın ağrısı, karında şişlik, bulantı ve kusma şikayetleri ile başvurdu. Yapılan tahlil ve tetkikler sonrasında hastada olanzapin kullanımına bağlı paralitik ileus tablosu düşünüldü. Medikal tedaviden fayda görmemesi üzerine hasta ameliyat edilerek ileostomi açılmıştır. Ameliyat öncesi başlanan neostigmin tedavisine ameliyat sonrası dönemde de devam edilmiş ve hasta 12. günde sorunsuz șekilde taburcu edilmiștir. Antipsikotik ilaç kullanımına bağlı paralitik ileusun tedavisinde öncelikle medikal tedaviler önerilse de bazı durumlarda zamanlaması doğru yapılmıș bir cerrahi müdahale, gelișebilecek morbidite ve mortalitenin önlenmesinde önem arz etmektedir. ( Sakarya Tip Dergisi 2019, 9(1):164-168)

Anahtar antipsikotik; olanzapin; paralitik ileus.

Ileus can develop due to opioid analgesics, tricyclic antidepressants, antihistamines, and antipsychotics. A 54-year-old male patient, who had been diagnosed with bipolar disorder under follow-up for about 30 years, presented with abdominal pain, abdominal swelling, nausea and vomiting that he had been experiencing for the last 5 days. The results of the examinations and tests suggested that he had paralytic ileus due to olanzapine administration. Upon the failure of medical treatment to enable recovery, the patient was taken into surgery and ileostomy was created. Neostigmine treatment, which was started preoperatively, was continued in the postoperative period as well and the patient was discharged on the 12th postoperative day without any problems. Although medical treatment modalities have been recommended initially for the treatment of paralytic ileus due to antipsychotic drug use, timely surgical intervention in some cases proves to be significant to prevent possible morbidity and mortality cases. (Sakarya Med J 2019, 9(1):164-168)

Key words antipsychotic; olanzapine; paralytic ileus 


\section{GIIRIŞ}

Geçirilmiş cerrahi dişında ileus için çeşitli risk faktörleri vardır. Bunlar hareket kısıtlılığı, kolorektal kanserler, diğer bazı bağırsak hastalıkları, lifli gıdalardan fakir beslenme ve bazı ilaçların kullanılması olarak sayılabilir. Opioid analjezikler, trisiklik antidepresanlar, antihistaminikler ve antipsikotik ilaçlara bağlı ileus gelişebilmektedir., ${ }^{1,2}$

Klozapin ve benzeri atipik antipsikotik ilaçların etkinliği oldukça fazla olmasına karşın agranülositoz, epileptik nöbet, hipotansiyon, aşırı kilo alma, siyalore gibi sık görülen yan etkileri kullanımını azaltmaktadır. ${ }^{3}$ Tüm bu sayılanlar dışında bağırsak tıkanıklı̆̆ı, paralitik ileus, kalın bağırsak perforasyonu, bağırsak nekrozu gibi durumlar ise bu ilaçların genellikle nadir görülen ve gözden kaçan, bu yüzden çoğu zaman ölümcül seyreden yan etkilerindendir. ${ }^{4}$

Bu çalışmada olanzapin kullanımına bağlı cerrahi müdahale gerektiren paralitik ileus olgusu sunulmuş ve literatürün gözden geçirilmesi amaçlanmıştır.

\section{OLGU SUNUMU}

Bipolar bozukluk tanısı ile yaklaşık otuz yıldır takipli olan 54 yaşında erkek hasta 5 gündür olan karın ağrısı, karında şişlik, bulantı ve kusma şikayetleri ile başvurdu. Uzun zamandır 10 mg olanzapin kullanan hastanın öz geçmişinde bu rahatsızlığı dışında başka bir hastalık ya da geçirilmiş cerrahi öyküsü yoktu. Daha önceden ara ara, kısa süreli kabızlık atakları olduğunu fakat bunların çoğu zaman kendiliğinden düzeldiğini, nadiren lavman uygulamasına ihtiyaç gösterdiğini ve hiçbir zaman bulantı-kusmasının olmadığını tarif etmekteydi. Hastanın son beş gündür ise ara ara gaz gaita deşarjı olmasına rağmen karında gittikçe artan bir şişlik, buna eşlik, yaygın kolik tarzda karın ağrısı, ağızdan beslenmesini engelleyen ciddi bulantı kusması olmuş. Çok defa lavman uygulanmış olmasına rağmen şikayetlerinde herhangi bir gerileme olmayan hasta acile başvurdu.

Yapılan fizik muayenede hasta hipotansif ve taşikardikti.
Mukozalar kuru görünümdeydi. Karın ileri derecede distandü, dinlemekle bağırsak sesleri azalmış ve yaygın hassasiyeti vard1. Rektal digital muayenede normal gaita bulaşı tespit edildi. Laboratuar bulgularında lökositoz, diğer akut faz reaktanlarında kısmi bir yükselme ve üre kreatinin değerlerinde artış saptandı. Ayakta direk karın grafisinde ince bağırsak düzeyinde seviyelenmeleri vardı (Şekil 1).

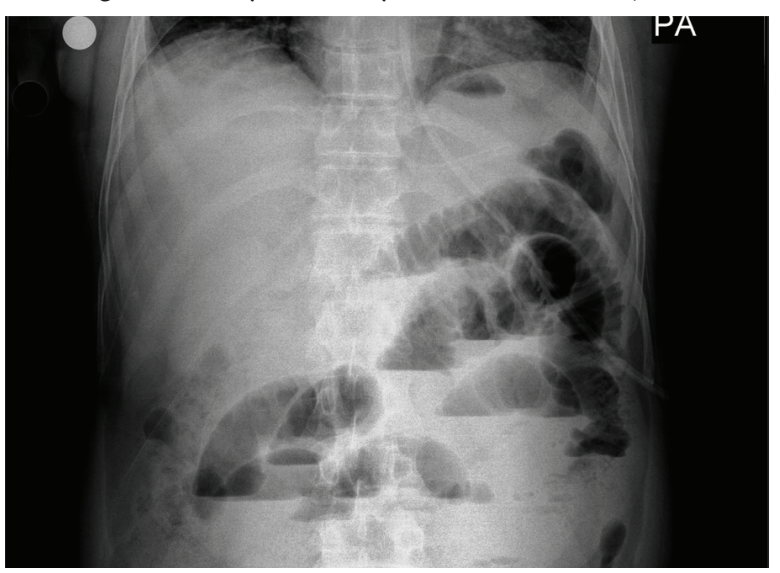

Şekil 1. Ayakta direk karın grafisinde ince bağırsak düzeyinde seviyelenme görüntüsü

Oral alımı tolere edemeyen hastaya ağızdan kontrast madde verilmeden çekilen bilgisayarlı karın tomografisinde ise jejunal-ileal ansların ileri derecede dilate, yer yer hava-sıvı seviyelerinin olduğu, pelvik bölgede bağırsak ansları arasında yer yer serbest sıvı ve mezenterik yağlı planlarda kirlenme olduğu görüldü. Bunun yanı sıra tıkanmaya sebep olabilecek belirgin bir odak görülmemekte, kalın bağırsak ansları da normal görünümde izlenmekteydi (Şekil 2).

Hastada antikolinerjik kullanımına bağlı paralitik ileus tablosu düşünülerek ön planda medikal takibi planlandı. Akut böbrek yetmezliği de olan hastada nazogastrik dekompresyon sağlanarak aldığı-çıkardığı takibi yapıldı. Hastanın olanzapin tedavi dozu azaltıldı. Uygun şekilde hidrasyonu ve mobilizasyonu sağlandı. Kolinerjik aktiviteyi artırmak için $2 \mathrm{mg} /$ gün neostigmin tedavisi başlandı. Yapılan 3 günlük medikal tedaviye rağmen kontrol grafilerinde seviyeleri belirginleşen, nazogastrik sondadan gelen içeriğin miktarı artan, akut böbrek yetmezliği bulguları ge- 
rilemeyen, distansiyona ikincil solunum sıkıntısı oluşmaya başlayan hastaya dekompresyonu sağlamak amacı ile acil şartlarda cerrahi müdahale planlandı. Ameliyat esnasında duodenumdan terminal ileuma kadar, proksimalde daha belirgin olmak üzere tüm ince bağırsak anslarının ileri derecede dilate ve ödemli olduğu, peristaltik dalgaların azaldığı, kolonik ansların ise normal görünümde olduğu saptandı. Bunun dışında mekanik bir tıkanıklığı düşündürecek herhangi bir bulgu yoktu. Hastada dekompresyon amaçlı uç ileostomi açıldı. Ameliyat sonrası dönemde neostigmin infüzyonuna devam edildi. Erken dönemde akut böbrek yetmezliği tablosu düzeldi. il̇esotomisi çalışır vaziyette olmasına rağmen distansiyonu ve seviyelenmeleri ancak 10. günde normale dönen hasta 12. günde sorunsuz şekilde taburcu edildi. Hastanın bağırsak alışkanlıkları normale geldikten sonra ileostomisinin kapatılması planlandi.

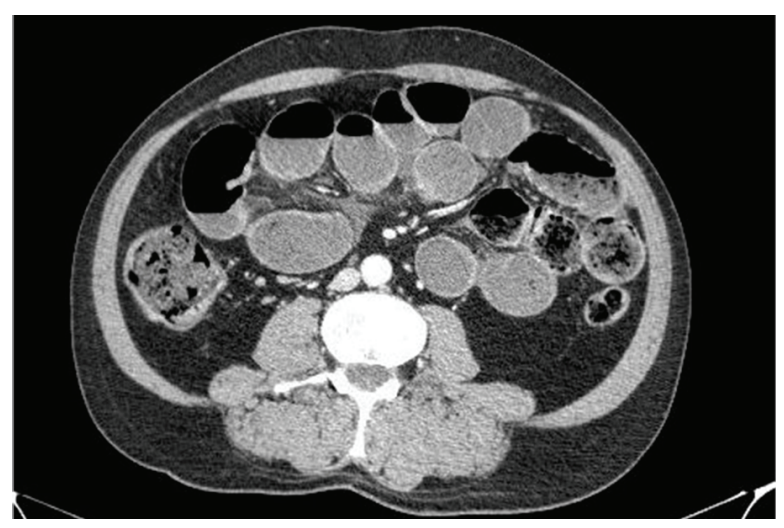

Şekil 2. Bilgisayarlı karın tomografisinde ince bağırsaklarda dilatasyon, seviyelenme, bağırsak ansları arasında serbest sıvı ve mezenterik yağlı planlarda kirlenme görüntüsü.

\section{TARTIŞMA}

Kabızlık antipsikotik ilaçların sık görülen bir yan etkisidir. Bazen tedavide gecikmeye bağlı kabızlığa ikincil bağırsak tıkanıklığı, iskemi ve perforasyon gibi yaşamı tehdit eden durumlar ortaya çıkabilmektedir. Bununla beraber Every-Palmer ve arkadaşlarının yaptığı bir çalışmada kolzapinin sadece kalın bağırsak değil, gastrointestinal sistemin çok farklı yerlerinde ciddi fonksiyon bozukluğuna sebep olabileceği gösterilmiştir.5 Paralitik ileus da antipsikotik ilaçların nadir fakat yaşamı tehdit eden bir yan etkisidir. Psikotik hastalarda ileus gelişimi için risk fakörlerinin incelendiği bir çalışmada ileri yaş ve artan dozlarda antipsikotik(özellikle klozapin) kullanımının ölümcül seyreden ileus gelişimi ile alakalı olduğu gösterilmiştir. ${ }^{6} \mathrm{Bi}-$ zim çalışmamızda da uzun zamandır olanzapin kullanım hikayesi olan hastada gelişen paralitik ileus vakası takdim edilmiştir.

Klozapin ve benzeri antipsikotik ilaçlarla gelişen ileusun bu ilaçların antikolinerjik etkisinden kaynaklandığı düşünülmektedir. İlaç kullanımı ve ileus gelişimi doz ve zaman bağımlı olduğu düşünülmektedir. ${ }^{7,8}$ Literatürde antipsikotik ilaç ilişkili paralitik ileus olgularının tamamına yakını klozapin kullanımı ile ilişkilidir. Olanzapinin potent antikolinerjik aktivitesine rağmen klozapinin aksine ileus riskinde herhangi bir artışa sebep olmadığı bildirilmektedir. $\mathrm{Bu}$ durumun olanzapinin antikolinerjik etkinliğinin, klozapinin ancak beşte biri kadar olmasından kaynaklandığ düşünülmektedir. ${ }^{9}$ Sunduğumuz olguda ise literatürdeki bu bilgi ile çelişkili olarak olanzapin kullanımına bağlı ciddi paralitik ileus tablosu gelişmiştir.

Psikotik hastalarda ileus gelişimini tetikleyecek bazı risk faktörleri de vardır. Yüksek doz antipsikotik ve antikolinerjik ilaç kullanımı, normal insanlara göre daha sedanter bir hayat sürüyor olmaları, ileri yaş, kadın cinsiyet bunlar arasında sayılmaktadır. ${ }^{4} \mathrm{Bu}$ hastalar normal bireylere göre daha geç bulgu vermekte ve hastaneye daha geç başvurmaktadır. Bu durumun, mevcut psikiyatrik rahatsızlık ve buna bağlı kullanılan ilaçların kişide ağrı eşiğini düşürmesi ile alakalı olduğu düşünülmektedir. ${ }^{10}$ Bizim hastamız da şikayetlerinin 5. gününde, akut böbrek yetmezliği geliştikten sonra, oldukça geç sayılabilecek bir dönemde başvurmuştur.

Antipsikotik ilaç kullanan ya da kullanacak hastalarda gastrointestinal sistemde meydana gelebilecek hipomotiliteye bağlı paralitik ileus ve diğer yan etkilerin önlenmesi 
ve tedavisinde bazı öneriler bulunmaktadır. Eğer hastada daha önceden bilinen bir kabızlık hikayesi varsa ilaç kullanımına başlamadan önce bu durum mümkünse tedavi edilmeli. Hasta gelişebilecek riskler konusunda bilgilendirilmeli, uygun diyet, yeterli sıvı alımı ve egzersiz konusunda desteklenmelidir. İlaç başlandıktan sonra erken dönemde hastaların bağırsak alışkanlıklarındaki oluşabilecek değişimler gözlenmelidir. Kabızlık gelişmiş olan hastalarda uygun dozda lavman kullanımı, kolinerjik bazı ajanların kullanımı fayda sağlayabilmektedir. ${ }^{7}$ Hastada karın ağrısı, distansiyon ve kusmanın eşlik ettiği ciddi gastrointestinal motilite bozukluğuna bağlı bir durum gelişirse neostigmin, fizostigmin gibi asetilkolin esteraz inhibitörlerinin bağırsak motilitesini artırmak yolu ile etkinliği olmaktadır. ${ }^{7}$ Bunun yanı sıra kolonda feçes birikimine bağlı bir ileus tablosu söz konusu ise lavman ve gerekirse rektal digital muayene ile katılaşmış feçesin çıkarılması tedavi edici olabilmektedir. ${ }^{7}$ Her ne kadar antipsikotik ilişkili paralitik ileus vakalarında ön planda medikal takip daha uygun bir yaklaşım olsa da bağırsaklarda tedaviye yanıtsız ciddi dilatasyon, iskemi ve perforasyon gibi durumlarda nadir de olsa cerrahi müdahale gerekebilmektedir. Bizim hastamizda da daha önceden ara ara olan ve lavman tedavisine yanıt veren kabızlık problemi olmuştur. Son başvurusunda ise gelişen paralitik ileus medikal tedaviye yanıt vermemiş, ciddi karın şişliğine ikincil solunum sıkıntısı, böbrek yetmezliği ve bağırsaklarda dilatasyon tablosunun düzelmemesi üzerine cerrahi müdahale gereği ortaya çıkmıştır.

Antipsikotik ilaç kullanımına bağlı paralitik ileusun tedavisinde öncelikle medikal tedaviler önerilse de bazı durumlarda zamanlaması doğru yapılmış bir cerrahi müdahale gelişebilecek morbidite ve mortalitenin önlenmesinde önem arz etmektedir.

\section{Çıkar çakışması beyanı}

Yazar bu yazının hazırlanması ve yayınlanması aşamasında herhangi bir çıkar çakışması olmadığını beyan etmiştir.

\section{Finansman}

Yazar bu yazının araştırma ve yazarlık sürecinde herhangi bir finansal destek almadığını beyan etmiştir. 
Sakarya Tip Dergisi 2019;9(1):164-168

\section{Kaynaklar}

1. De Hert M, Hudyana H, Dockx L, Bernagie C, Sweers K, Tack J et al. Second-generation antipsychotics and constipation: a review of the literature. Eur Psychiatry 2011 Jan;26(1):3444. doi:10.1016/j.eurpsy.2010.03.003.

2. Peyrière H, Roux C, Ferard C, Deleau N, Kreft-Jais C, Hillaire-Buys D et al. Antipsychotics-induced ischaemic colitis and gastrointestinal necrosis: a review of the French pharmacovigilance database. Pharmacoepidemiol Drug Saf 2009 Oct;18(10):948-55. doi:10.1002/ pds.1801.

3. Young CR, Bowers MB Jr, Mazure CM. Management of the adverse effects of clozapine. Schizophr Bull 1998;24(3):381-90. doi:10.1093/oxfordjournals.schbul.a033333.

4. Raja M, Raja S. Clozapine safety, 40 years later. Curr Drug Saf 2014;9(3):163-95. PMID: 24809463.

5. Every-Palmer S, Inns SJ, Grant E, Ellis PM. Effects of Clozapine on the Gut: Cross-Sectional Study of Delayed Gastric Emptying and Smalland Large Intestinal Dysmotility. CNS Drugs.
2019 Jan:33(1):81-91. doi: 10.1007/s40263-018-0587-4.

6. Nielsen J, Meyer JM. Risk factors for ileus in patients with schizophrenia. Schizophr Bull 2012 May;38(3):592-8. doi:10.1093/schbul/sbq137.

7. Palmer SE, McLean RM, Ellis PM, Harrison-Woolrych M. Life-threatening clozapine induced gastrointestinal hypomotility: an analysis of 102 cases. J Clin Psychiatry 2008 May;69(5):759-68. PMID: 18452342.

8. Fayad SM, Bruijnzeel DM. A fatal case of adynamic ileus following initiation of clozapine. Am J Psychiatry 2012 May;169(5):538-9. doi:10.1176/appi.ajp.2012.11111625.

9. Chengappa KN, Pollock BG, Parepally H, Levine J, Kireshner MA, Brar JS et al. Anticholinergic differences among patients receiving standard clinical doses of olanzapine or clozapine. J Clin Psychopharmacol 2000 Jun;20(3):311-6. PMID: 10831017.

10. Dworkin RH. Pain insensitivity in schizophrenia: a neglected phenomenon and some implications. Schizophr Bull 1994; 20: 235-48. doi:10.1093/schbul/20.2.235. 